\title{
Pyrococcus furiosus flagella: biochemical and transcriptional analyses identify the newly detected flaBO gene to encode the major flagellin
}

\author{
Daniela J. Näther-Schindler ${ }^{1,2}$, Simone Schopf ${ }^{1,3}$, Annett Bellack ${ }^{1 *}$, Reinhard Rachel $^{1}$ and \\ Reinhard Wirth ${ }^{1}$ \\ 1 Institute of Microbiology and Archaea Center, University of Regensburg, Regensburg, Germany \\ 2 Plant Development, Department of Biology I, Biocenter of the Ludwig Maximilian University of Munich, Planegg-Martinsried, Germany \\ ${ }^{3}$ Department of Biology - Section Environmental Microbiology, Technical University Freiberg, Freiberg, Germany
}

\section{Edited by:}

Mechthild Pohlschroder, University of Pennsylvania, USA

Reviewed by:

Dirk Linke, Max Planck Society, Germany

Friedhelm Pfeiffer,

Max-Planck-Institute of

Biochemistry, Germany

\section{${ }^{*}$ Correspondence:}

Daniela J. Näther-Schindler, Plant

Development, Department of

Biology I, Biocenter of the Ludwig

Maximilian University of Munich,

Großhadernerstr. 2-4, 82152

Planegg-Martiensried, Germany

e-mail: daniela.naether@gmx.de,

Annett Bellack, Institute of

Microbiology and Archaea Center,

University of Regensburg,

Universitaetsstr. 31, 93053

Regensburg, Germany

e-mail: annett.bellack@ur.de
We have described previously that the flagella of the Euryarchaeon Pyrococcus furiosus are multifunctional cell appendages used for swimming, adhesion to surfaces and formation of cell-cell connections. Here, we characterize these organelles with respect to their biochemistry and transcription. Flagella were purified by shearing from cells followed by CsCl-gradient centrifugation and were found to consist mainly of a ca. $30 \mathrm{kDa}$ glycoprotein. Polymerization studies of denatured flagella resulted in an ATP-independent formation of flagella-like filaments. The $\mathrm{N}$-terminal sequence of the main flagellin was determined by Edman degradation, but none of the genes in the complete genome code for a protein with that $\mathrm{N}$-terminus. Therefore, we resequenced the respective region of the genome, thereby discovering that the published genome sequence is not correct. A total of $771 \mathrm{bp}$ are missing in the data base, resulting in the correction of the previously unusual $\mathrm{N}$-terminal sequence of flagellin FlaB1 and in the identification of a third flagellin. To keep in line with the earlier nomenclature we call this flaBO. Very interestingly, the previously not identified flaBO codes for the major flagellin. Transcriptional analyses of the revised flagellar operon identified various different cotranscripts encoding only a single protein in case of FlaBO and FlaJ or up to five proteins (FlaBO-FlaD). Analysing the RNA of cells from different growth phases, we found that the length and number of detected cotranscript increased over time suggesting that the flagellar operon is transcribed mostly in late exponential and stationary growth phase.

\section{INTRODUCTION}

Archaea have been shown to possess various distinct types of cell surface appendages (reviewed e.g., by Ng et al., 2008 or Jarrell et al., 2013) of which flagella are the best characterized ones. Superficially, these structures seem to be very similar to bacterial flagella; however, analyses of the ultrastructure, the involved proteins and the biosynthesis machinery identified fundamental differences (see e.g., Thomas et al., 2001 or Ghosh and Albers, 2011 for reviews on archaeal flagella). Based on these findings a renaming of archaeal flagella into archaella has been suggested (Jarrell and Albers, 2012) but has been questioned because of serious flaws as consequences of such a nomenclature (Wirth, 2012). With respect to the ongoing discussion about a name reflecting the function and uniqueness of these cell surface structures, we decided to retain the term flagella.

Archaeal flagella are built in their part emanating from the cell from mostly more than one protein, the so-called flagellins. In silico analyses of many different archaeal genomes found that the genes encoding flagellins (flaA and/or flaB) are arranged in an operon together with additional proteins assumed to be motor and anchoring components. In Euryarchaeota, the operon comprises the fla-associated genes flaC to flaJ, whereas in Crenarchaeota, flaCDE are missing and flaX is present (which is absent from Euryarchaeota). Interestingly, neither these genes nor the corresponding proteins show any similarities to their bacterial counterparts (Jarrell et al., 2013). Hence, our current knowledge of the assembly of archaeal flagella is based on genetic analyses. Deletion studies in Halobacterium salinarum, Methanococcus maripaludis, and Sulfolobus acidocaldarius have shown that all of the fla-associated genes are necessary for proper assembly and function of flagella (Patenge et al., 2001; Chaban et al., 2007; Lassak et al., 2012). Flagellins are synthesized as preproteins; their signal peptide is removed by FlaK and an N-linked glycan is attached by the oligosaccharyltransferase AglB. These posttranslationally modified subunits are supposed to be incorporated at the base of the growing non-tubular structure involving the activity of the ATPase FlaI and the conserved membrane protein FlaJ (Jarrell et al., 2013).

In addition to the mentioned mesophilic and thermophilic species, the Euryarchaeon Pyrococcus furiosus is a model organism 
for hyperthermophilic Archaea. Despite the availability of a genetic system (Waege et al., 2010; Lipscomb et al., 2011) and numerous -omics-based approaches (for a summary see Bridger et al., 2012), data on its flagella are restricted to a publication of our group (Näther et al., 2006). We have shown that $P$. furiosus uses its flagella not only for swimming, but is able to adhere with these cell surface organelles to specific surfaces including cells of its own species, thereby forming biofilms. In addition, also the formation of cell-cell connections via cable-like aggregated flagella was observed (Näther et al., 2006). In further studies we have demonstrated that also the flagella of the fastest organisms on earth (Herzog and Wirth, 2012), namely the Euryarchaeon Methanocaldococcus villosus, can be used for adhesion to various surfaces; again, also formation of cell-cell connections by flagella was described (Bellack et al., 2011). Beside the functional studies, we have proven that the flagella of $P$. furiosus consist of mainly one glycoprotein (Näther et al., 2006), but the N-terminal sequence we identified did not match perfectly to any protein annotated in the published genome sequence (Robb et al., 2001). Therefore, we resequenced the flagellar operon in this study and discovered that a 771 bp segment was missing previously in the genome sequence. On this segment, we identified an in-frame start codon for the flaB1 gene and a new gene, flaB0, which encodes the major flagellin. In addition we performed in vitro polymerization studies of flagellin monomers and analyzed transcription of the revised flagellar operon of $P$. furiosus.

\section{MATERIALS AND METHODS \\ GROWTH OF P. FURIOSUS, FLAGELLA PREPARATION, AND REPOLYMERIZATION OF DENATURATED FLAGELLINS}

Growth of cells and preparation of flagella therefrom by shearing followed by CsCl-gradient centrifugation was as described (Näther et al., 2006). For repolymerization studies, flagella were isolated as follows: cells were lysed by osmotic shock; membranes were then harvested by differential centrifugation and solubilized overnight at room temperature by addition of $0.5 \%$ $\mathrm{n}$-dodecyl $\beta$-D-maltopyranoside (DDM). After purification by CsCl-gradient centrifugation (Näther et al., 2006), flagella were denatured by addition of SDS to a final concentration of $1 \%$ and heating at $100^{\circ} \mathrm{C}$ for $30 \mathrm{~min}$. The samples were dialyzed four times for $1 \mathrm{~h}$ each against $5 \mathrm{mM}$ HEPES buffer $(\mathrm{pH}=7.0)$, followed by an overnight dialysis. These samples were incubated in tightly closed vials at various temperatures $\left(8^{\circ} \mathrm{C}, 37^{\circ} \mathrm{C}, 60^{\circ} \mathrm{C}\right.$, and $90^{\circ} \mathrm{C}$ ) with/without addition of $1 \mathrm{mM}$ ATP. To avoid evaporation samples incubated at $60^{\circ} \mathrm{C}$ and $90^{\circ} \mathrm{C}$ were overlaid with chillout liquid wax (Biorad Laboratories GmbH; Munich, Germany). Aliquots were analyzed by SDS-PAGE after 1, 2, and 6 days, without heating prior to loading.

$\mathrm{N}$-terminal sequencing by Edman degradation was performed by the protein analytic facility of the Biochemistry Department of the University of Regensburg.

\section{DNA ISOLATION AND SEQUENCING}

For DNA isolation cells were collected from $40 \mathrm{ml}$ cultures by centrifugation and DNA was isolated according to Bellack et al. (2011). Alternatively, cells were resuspended in $0.8 \mathrm{ml}$ TNE buffer (100 mM Tris/Cl; 50 mM NaCl; 50 mM EDTA; $\mathrm{pH}=8.0$ ). Lysis of cells was by addition of $0.1 \mathrm{ml}$ of $10 \%$ SDS plus $0.1 \mathrm{ml}$ of $10 \% \mathrm{~N}$-lauroylsarcosine and cautious mixing. After addition of $10 \mu \mathrm{l}$ RNase $(10 \mathrm{mg} / \mathrm{ml})$ and incubation for $15 \mathrm{~min}$ at roomtemperature $50 \mu \mathrm{l}$ proteinase $\mathrm{K}(20 \mathrm{mg} / \mathrm{ml})$ was added and the sample heated for $1 \mathrm{~h}$ to $55^{\circ} \mathrm{C}$. After repeated phenol extractions DNA was precipitated from the water phase with $800 \mu l$ 2 -propanol, the pellet was washed with $70 \%$ ice-cold ethanol and dissolved in water.

For resequencing of the genomic region around the flaB2 gene, primer walking analyses were performed using primers $353420_{\mathrm{f}}\left(5^{\prime}\right.$-ATGGAAAAACTAGAGAAGACCGTTG-3 $\left.{ }^{\prime}\right), 352920_{\mathrm{f}}$

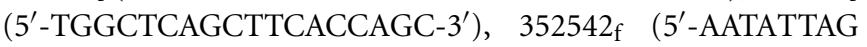
ATGAGGGATTCGAAGTTAA- $\left.3^{\prime}\right), \quad 352509_{\mathrm{f}} \quad\left(5^{\prime}\right.$-GGATTATG GAAAGGCAATTCTTCTC-3' $\left.{ }^{\prime}\right), 353159_{\mathrm{r}} \quad\left(5^{\prime}\right.$-TATTGCCATCTT AACTATGGTCCC- $3^{\prime}$ ), and 351761 $1_{\mathrm{r}}$ (5'-ATCACATTATACTCAA ATGTTGGGG-3'). Primer numbers refer to the binding position in the original genome sequence (Robb et al., 2001).

PCR reactions using primers $353483_{\mathrm{f}}$ ( $5^{\prime}$-GGATTATGGAAA GGCAATTCTTCTC-3') and 351761 $1_{\mathrm{r}}$ were used to analyze genomic DNA from various $P$. furiosus strains for the presence of the flaBO gene.

\section{GENERATION OF ANTIBODIES}

To raise specific antibodies against each flagellin, the respective central region (Figure 2, gray sequences) was amplified via PCR using primers FlaB0-MT $\mathrm{M}_{\mathrm{f}}\left(5^{\prime}-\right.$ GGATCCGAGAAAACAGCATATCACAAAGGA-3' $3^{\prime}$, FlaB0-MT $\mathrm{T}_{\mathrm{r}}$

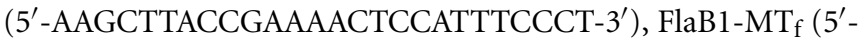
GGATCCAGTGGAGAACTGTACACTGGAAAGA-3'), FlaB1$\mathrm{MT}_{\mathrm{r}}$ (5'-AAGCTTGCTCTTATAATTAAAGACATCATCCGT-3' ${ }^{\prime}$,

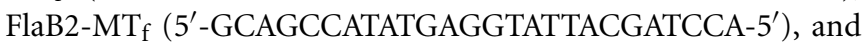
FlaB2-MT $\mathrm{M}_{\mathrm{r}}$ (5'-GAAGGGGATCCTCAGTAGAGGTTCCA-5' $\left.{ }^{\prime}\right)$. Fragments were cloned into the low-copy number plasmid pQE30 (QIAGEN; Hilden, Germany) to avoid instable clones. The plasmid was transformed into the E. coli expression strain BL21 Star(DE3)pLysS; the corresponding $\sim 6 \mathrm{kDa}$ peptides could be purified after induction with IPTG via Ni-chelate chromatography and were used to immunize rabbits (Davids Biotechnologie; Regensburg, Germany).

\section{ISOLATION OF RNA, REVERSE TRANSCRIPTION PCR, AND NORTHERN BLOT EXPERIMENTS}

$500 \mathrm{ml}$ of exponentially growing cells $\left(\sim 1 \times 10^{7}\right.$ cells $/ \mathrm{ml}$ and $4-5 \times 10^{7}$ cells $/ \mathrm{ml}$; direct cell counting using a Thoma counting chamber) or stationary cells $\left(\sim 2 \times 10^{8}\right.$ cells $\left./ \mathrm{ml}\right)$ were collected by centrifugation and resuspended in $1 \mathrm{ml}$ of Trizol ${ }^{\mathrm{TM}}$ each. After incubation for $10 \mathrm{~min}$ at room temperature $0.2 \mathrm{ml}$ chloroform was added and the lysate was cautiously mixed. After centrifugation $\left(12,000 \times \mathrm{g}, 15 \mathrm{~min}, 4^{\circ} \mathrm{C}\right)$ the water phase was collected, $0.5 \mathrm{ml}$ ice-cold 2-propanol was added and precipitation was for $30 \mathrm{~min}$ or overnight at $-20^{\circ} \mathrm{C}$. RNA was collected by centrifugation as above and the pellet was washed with $1 \mathrm{ml}$ of ice-cold $70 \%$ ethanol. The pellet was air dried, resuspended in $100 \mu \mathrm{H} \mathrm{H}_{2} \mathrm{O}$ and $90 \mu \mathrm{l}$ DNase I Incubation Buffer plus $10 \mu \mathrm{l}$ DNase I (both from High Pure RNA Isolation Kit, Roche Diagnostics GmbH; Mannheim, Germany) were added. After $15 \mathrm{~min}$ incubation at room temperature further processing, 
including a phenol/chloroform extraction and RNA precipitation, was as recommended in the High Pure RNA Isolation Kit.

To detect specific mRNA transcripts, mRNA was transcribed into cDNA using the Super Script II reverse Transcriptase protocol as suggested by the supplier (Invitrogen GmbH; Karlsruhe, Germany). The various cDNAs were amplified via PCR using different combination of primers which were designed for each gene of the flagellar operon; primers are given in Supplementary Figure S1. In each case a negative control without addition of cDNA was included; the positive control included PCR reactions using genomic DNA.

For Northern Blotting, RNA probes were labeled with digoxygenin using the DIG Northern Starter Kit (Roche Diagnostics GmbH; Mannheim, Germany). Gel electrophoresis, northern blot, hybridization and detection was as recommended in the manufacturer's instructions.

\section{TEM ANALYSES}

Preparation of specimens by negative staining and for immunolabeling was as described earlier (Näther et al., 2006; Rachel et al., 2010).

\section{RESULTS}

\section{IDENTIFICATION OF flaBO, A THIRD FLAGELLAR GENE, IN THE GENOME OF P. FURIOSUS}

Purification of flagella via isopycnic CsCl-gradient centrifugation and analysis by SDS-PAGE identified one major glycoprotein, whose N-terminal amino acid sequence was determined to be AVGIGTLIVF (Näther et al., 2006). Sequence alignments illustrated that this $\mathrm{N}$-terminal sequence did not perfectly match to the annotated flagellins of $P$. furiosus or to any of the other proteins translated from the published genome (Robb et al., 2001). More precisely, the N-terminus of protein FlaB2 should read AIGIGTLIVF, but Edman degradation of the major flagellin never indicates any heterogeneity at position 2 . In case of protein FlaB1 we found that the published sequence lacks the motif AIGIGTLIVFIAM, which is very highly conserved in all flagellins annotated in the publically available genomes of the genus Pyrococcus. However, this motif is encoded directly in front of the annotated flaB1 gene but misses an upstream in-frame start codon. Based on these findings we decided to resequence the genome region that codes for the flagellins. Indeed, we identified a major mistake in that part of the published $P$. furiosus genome sequence: a total of $771 \mathrm{bp}$ are missing. By combining this new sequence with the published genome (Robb et al., 2001), the sequence of the flaB1 gene now contains a proper start codon and its N-terminus becomes highly similar to other flagellins. In addition, we detected another ORF coding for a third flagellin which we call flaBO to keep in line with the existing nomenclature. As a consequence, the flagellar operon of $P$. furiosus was revised (Figure 1). The missing genomic sequence containing the annotation of the flaBO gene/FlaB0 protein was submitted to NCBI BankIt; the corresponding GenBank number is KM892551.

\section{FlaBO, THE MAJOR FLAGELLIN OF P. FURIOSUS}

All flagella isolated from $P$. furiosus by different methods (shearing, DDM treatment, Triton X-114 treatment according to Kalmokoff et al., 1988) over a period of nearly 10 years were composed of one major flagellin as indicated by SDS-PAGE. The finding that the N-terminal amino acid sequence of this protein unambiguously was AVGIGTLIVF suggests that the newly

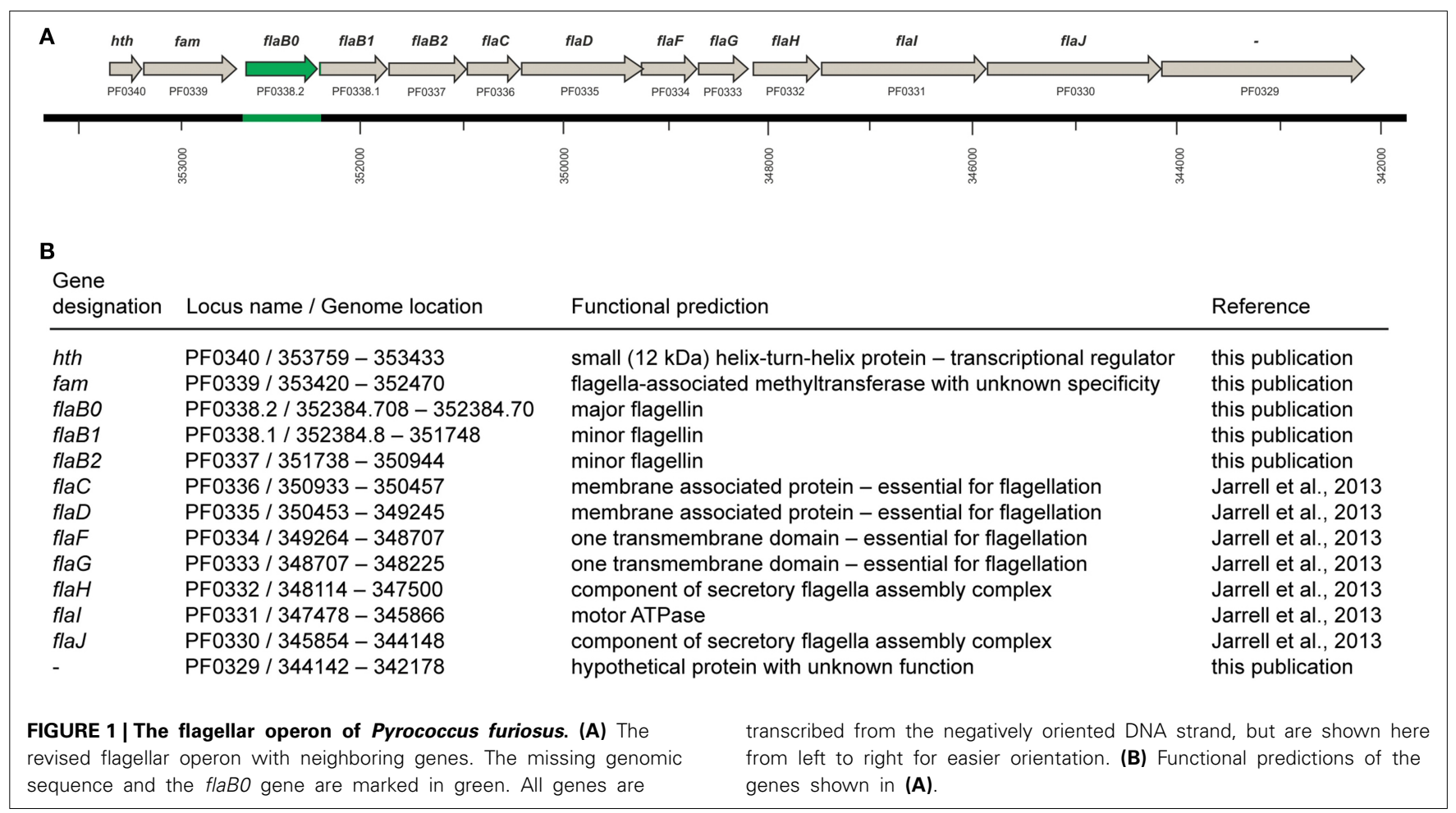


detected FlaB0 is the major flagellin of $P$. furiosus whereas FlaB1 and FlaB2 are only minor flagellins.

To ask for the presence of the two minor flagellins in our flagella preparations, we raised specific antibodies against all three flagellins. Because of the highly conserved $\mathrm{N}$ - and C-terminal part of FlaB0, FlaB1, and FlaB2, we subcloned the unique central part of each flagellin (gray sequences in Figure 2) and used the peptides for immunization of rabbits. The resulting antisera had a low titer, especially for the FlaB2-peptide. Western blots (data not shown) using these antisera proved that all three flagellins are present in the protein band at around $30 \mathrm{kDa}$. In addition, purified antibodies were used to immuno-label flagella preparations and cells adherent to carbon-coated gold grids for TEM. Again, we could show that antibodies against sheared $P$. furiosus flagella detach adherent cells from their solid support as described earlier (Näther et al., 2006). Some single cells, however, remained on the grid and their flagella were clearly labeled over their whole length. In contrast, no signals were detected using any of the antibodies against the recombinant flagellin middle parts. Specific antibodies against FlaB1 and FlaB2 reacted mostly with the ends of purified flagella (data not shown).

\section{DENATURATED FLAGELLA CAN REPOLYMERIZE INTO FILAMENTOUS STRUCTURES}

We furthermore asked if "native flagella" could be repolymerized from denatured flagellins, spontaneously without energy and without a template. For depolymerization a flagella preparation was denatured by addition of SDS and incubation at $100^{\circ} \mathrm{C}$, followed by extensive dialysis. We found that heat treatment is necessary for complete denaturation, otherwise SDS-PAGE shows the presence of minor protein bands with molecular weights of ca. 60, 90, and $>100 \mathrm{kDa}$. Two dimensional SDS-PAGE clearly proved that these bands could be dissociated into the $\sim 30 \mathrm{kDa}$ flagellin monomers (data not shown).

Flagellins from denaturated flagella were incubated at different temperatures to analyze their potential to repolymerize. Incubation for 1 day or longer at temperatures higher than $60^{\circ} \mathrm{C}$ resulted in aggregation of the $\sim 30 \mathrm{kDa}$ flagellins into highmolecular weight polymers, forming in part also filamentous structures as proven by TEM (Figure 3). Comparing these filaments to native flagella, we found the diameter to be smaller, and no helical ultrastructure was present. Addition of ATP to the samples had no influence on the formation of aggregates or filaments (data not shown).

\section{CONSERVATION OF FlaBO IN VARIOUS P. FURIOSUS STRAINS}

The genome of $P$. furiosus has been reported to be dynamic (Bridger et al., 2012) - a feature of this hyperthermophile we experienced also in our Regensburg labs. Over the years, we have identified at least 2 strains differing from the original $P$. furiosus isolate whose origin/history is shown in Figure 4. The original strain named Vcl was deposited as type strain DSM $3638^{\mathrm{T}}$

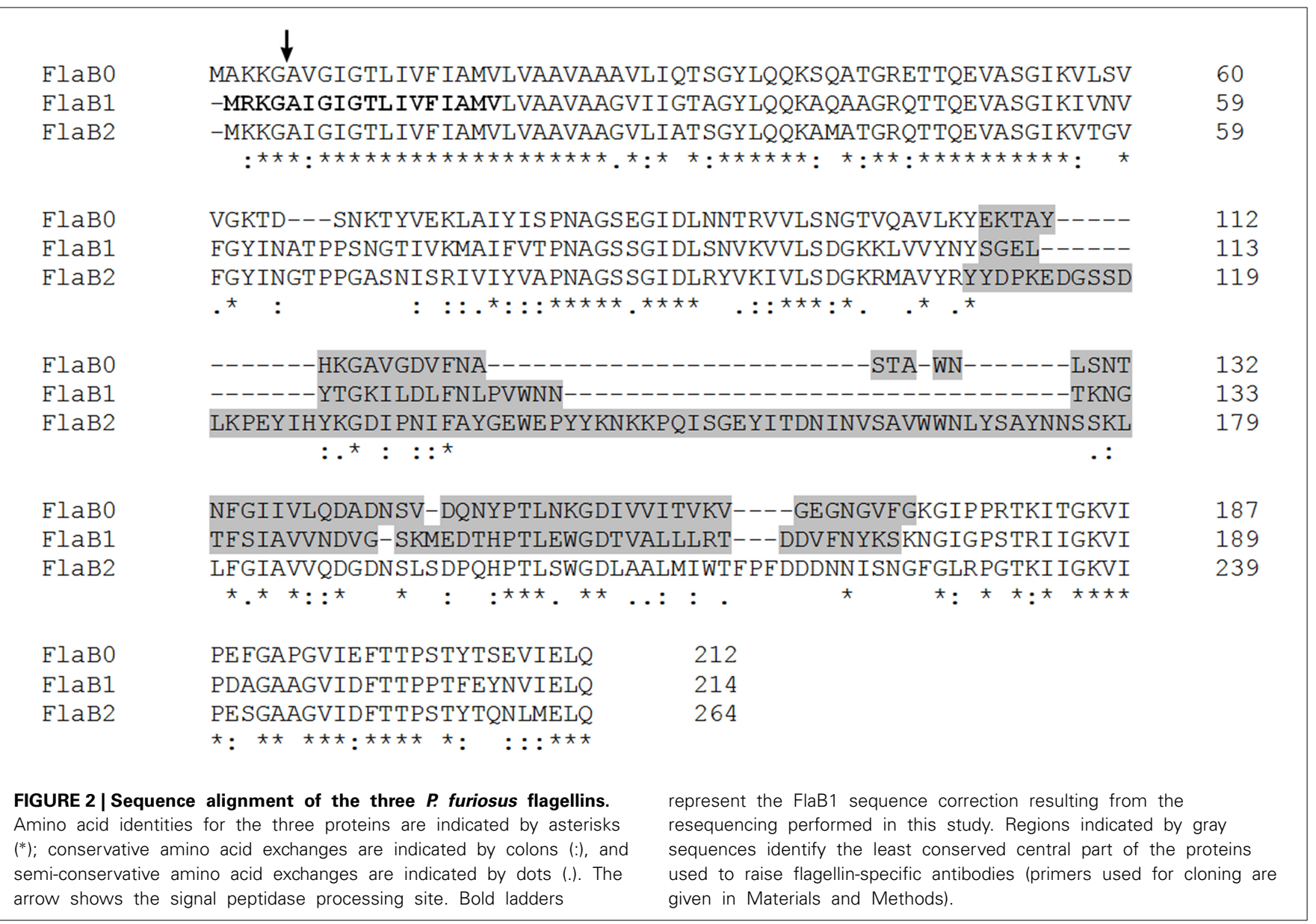




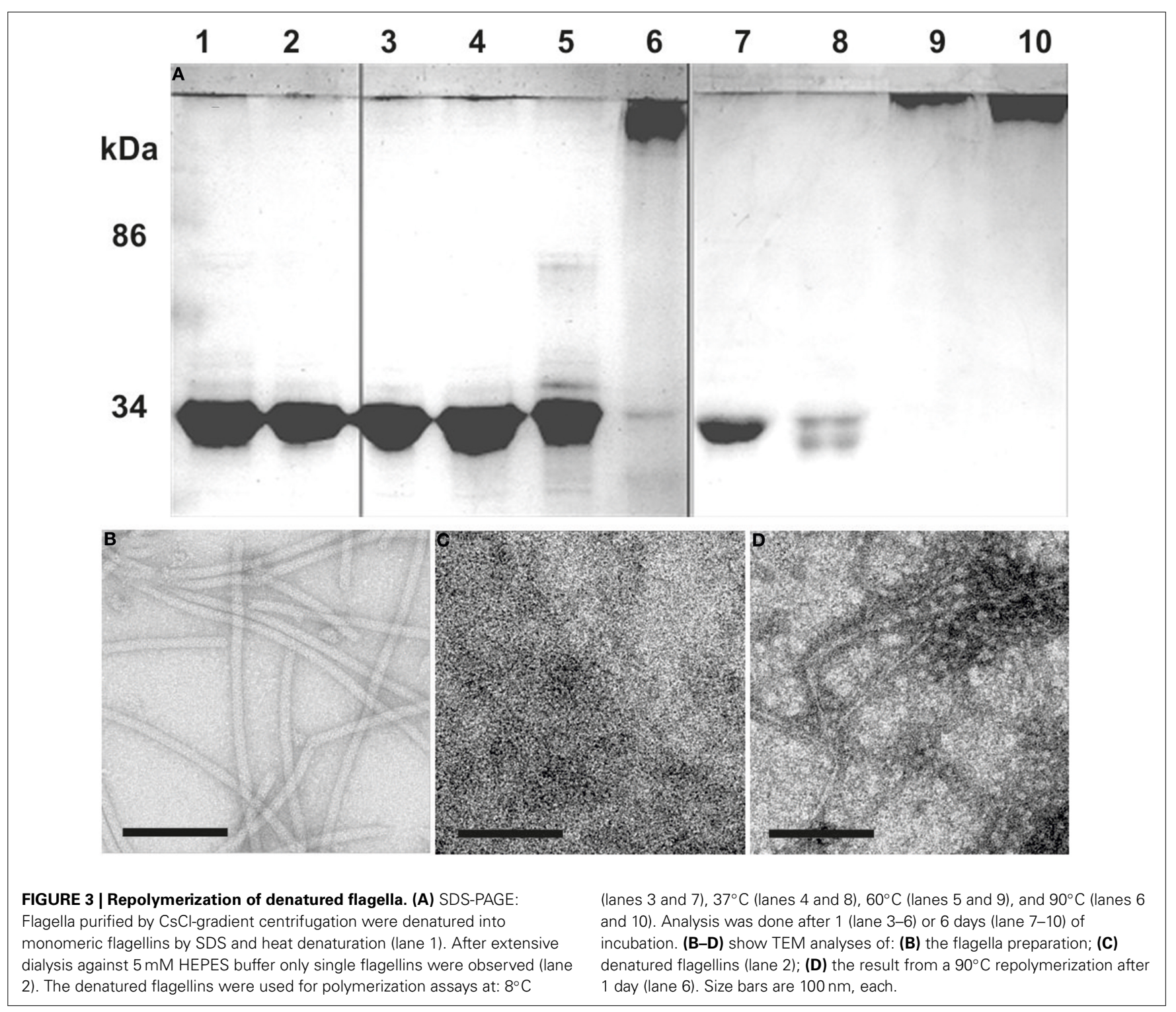

at the German Culture Collection (Deutsche Sammlung für Mikroorganismen und Zellkulturen, DSMZ) ca. 6 months after its isolation. The same isolate was repeatedly regrown (for ca. 7 years) from stocks stored at $4^{\circ} \mathrm{C}$ and deposited in 1992 in our Regensburg Culture Collection, (Bakterienbank Regensburg, BBR). Therefrom strain LS was regenerated in 2004 and was repeatedly regrown from stocks stored at $4^{\circ} \mathrm{C}$. Another derivate, strain BBR was regenerated from our in-house culture collection in 2008 and repeatedly regrown from stocks stored at $4^{\circ} \mathrm{C}$. The three strains of $P$. furiosus, namely $\mathrm{Vcl}^{\mathrm{T}}$, LS, and $\mathrm{BBR}$, differ with respect to their binding behavior to various surfaces if tested as described (Näther et al., 2006), they express different amounts of flagella and their cell morphology differs drastically (Bellack, 2011; data will be described in detail elsewhere).

We therefore asked if the newly discovered flagellin gene flaBO is conserved not only in the type strain but also in the two lab derivates. Hence, genomic DNA was isolated and primers $353483_{\mathrm{f}}$ and $351761_{\mathrm{r}}$ were used to amplify the region around flaB0. For all three strains a $2.5 \mathrm{~kb}$ fragment was amplified as expected for the presence of flaBO (Figure 5). As the primer numbers refer to the binding position in the public genome of $P$. furiosus (Robb et al., 2001 ), the fragment should be only $1.7 \mathrm{~kb}$ in length when no flaBO would be present. Genomic sequencing of the flaBO region confirmed the sequence we determined earlier for the missing $771 \mathrm{bp}$ segment in all three strains (data not shown).

\section{TRANSCRIPTIONAL ANALYSES OF THE P. FURIOSUS FLAGELLAR OPERON}

We asked if all flagella-related genes of $P$. furiosus would be transcribed together, or if various smaller transcripts might exist. Transcripts were analyzed by PCR after reverse transcription of mRNA into CDNA, the positive control used genomic DNA instead. A negative control without addition of $\mathrm{CDNA}$ proved that in all cases only transcripts from mRNA were analyzed (data not shown). 


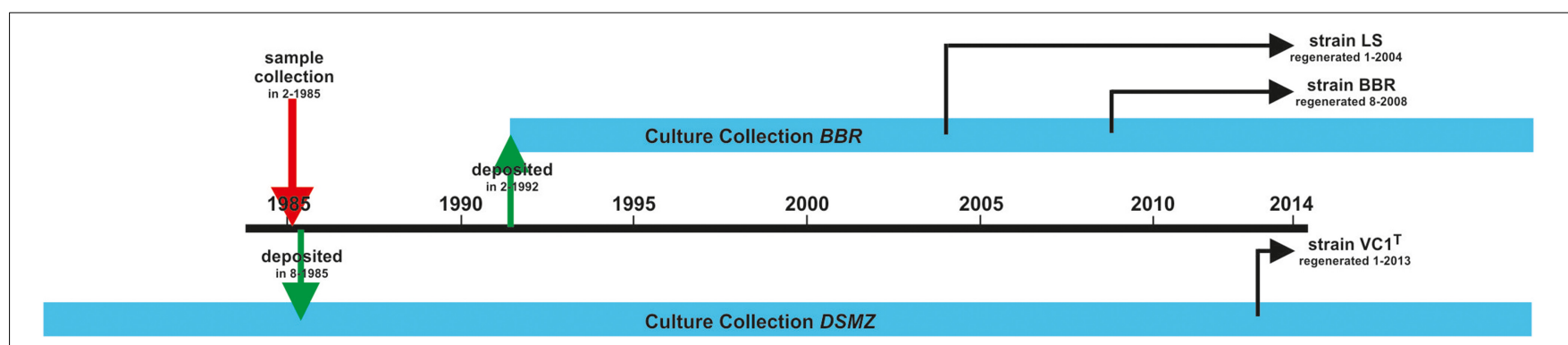

FIGURE 4 | History of the $\boldsymbol{P}$ furiosus strains used in this study. The type strain $\mathrm{Vc}_{\mathrm{c}}^{\top}$ was deposited within 6 months after its isolation at DSMZ. Strains $P$. furiosus LS and BBR were regenerated at different times from our in-house culture collection and thereafter repeatedly grown and stored at $4^{\circ} \mathrm{C}$.

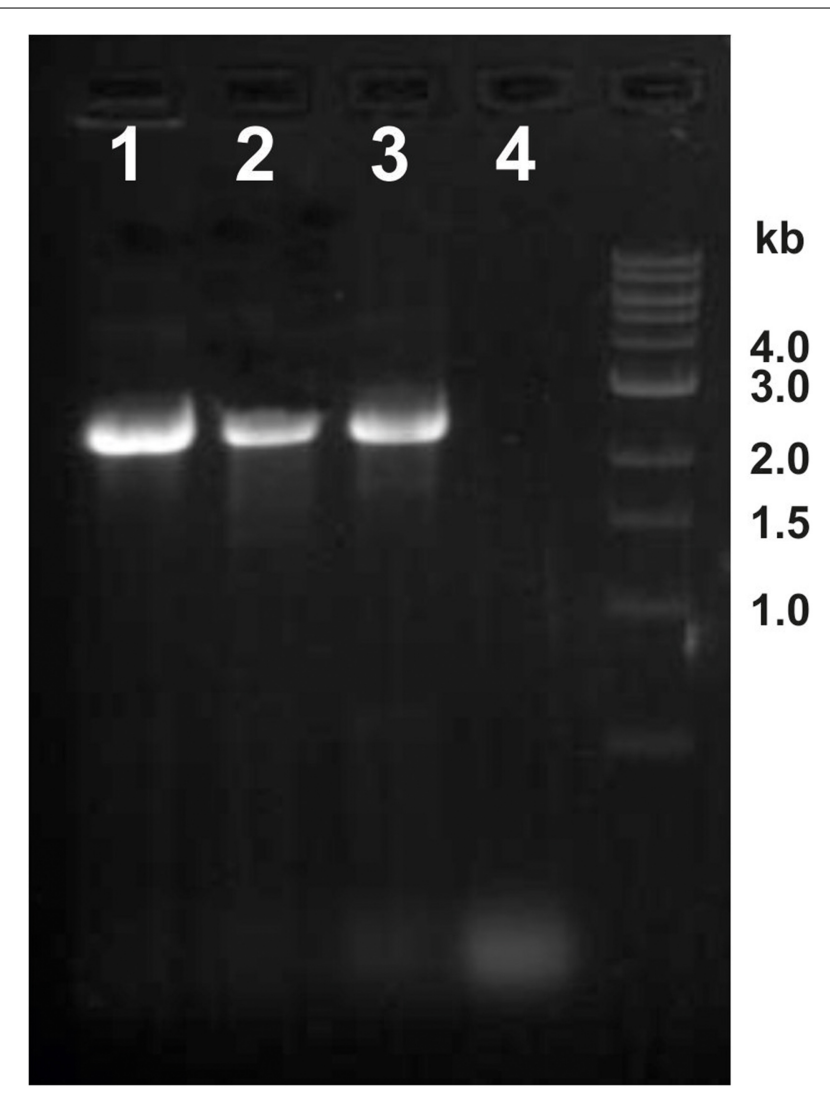

FIGURE 5 | Detection of the flaBO gene in three different $\boldsymbol{P}$ furiosus strains. Genomic DNA was isolated from the three strains $P$. furiosus $V_{c} 1^{\top}$, $B B R$, and LS and used for PCR amplification with primers $353483_{f}$ and $351761_{\mathrm{r}}$. Very clearly a ca. $2.5 \mathrm{~kb}$ amplificate was identified in all three strains; if flaBO would be missing (as in the original sequence) a ca. $1.7 \mathrm{~kb}$ amplificate would be expected. Lane 1, strain LS; lane 2, strain BBR; lane 3, strain $\mathrm{Vc}_{\mathrm{c}}{ }^{\top}$; lane 4, negative control.

We detected different length cotranscripts for each of the genes of the flagellar operon with exception of flaJ were only the single gene transcript was found (Figure 6A). The original data using the different primers are shown exemplarily for flaBO in Figures 6B,C, all other data are given in Supplementary Figure $\mathrm{S} 1$. Several transcripts including flaBO were found whereof the largest with ca. $3.1 \mathrm{~kb}$ contained all three flagellins, flaC, and
flaD. Besides, various transcripts for the genes flaF-flaI were detected. Interestingly, we found a transcript containing $h t h$ and fam whereas flaJ and PF0329 were never part of a cotranscript. Analyses of RNA of cells from different growth phases showed that the transcripts changed over time; the original data are shown exemplarily in Figure 7. In early exponential phase, only few short transcripts were present compared to late exponential and stationary phase indicating that the flagellar operon is transcribed only to a limited degree in early exponential growth phase.

Northern blot experiments using RNA isolated from late exponentially growing cells showed the existence of a prominent $\mathrm{ca}$. $600 \mathrm{bp}$ long transcript using a probe for flaB0. In addition a much less prominent smear above ca. $4 \mathrm{~kb}$ was detected (Figure 6D). For cells in the stationary growth phase, only the $\sim 600$ bp long flaBO transcript was detected.

\section{DISCUSSION \\ DIFFICULTIES TO CLONE flaBO MIGHT HAVE PREVENTED ITS IDENTIFICATION IN GENOME SEOUENCING}

The genome of $P$. furiosus was one of the first archaeal genomes to be sequenced (Robb et al., 2001). In those "old days" of genome sequencing the shotgun cloning and sequencing approach - first used by the Venter lab to determine the Haemophilus influenzae genome (Fleischmann et al., 1995) — was the only way to obtain reliable data. A general problem with this approach is the fact that some genes are difficult to clone or might be even toxic for the host, normally Escherichia coli. In our studies, we found that flaBO could not be cloned into E. coli using standard approaches. Cloning in a vector system with expression under the strong T7 polymerase promoter as used e.g., for cloning of flagellins of Methanococcus voltae (Bayley and Jarrell, 1999) or in the IMPACT system (intein-mediated purification with an affinity binding tag) failed since the protein turned out to be toxic. We furthermore experienced problems with subcloning parts of $P$. furiosus flagellin genes, which was especially true for flaB0. Only the middle part of flaBO could be cloned, but not the $\mathrm{N}$ - and C-terminal regions. Hence, we suggest that these problems in cloning might also have happened during the original genome sequencing.

The only way we could obtain the flaBO sequence was to sequence directly from genomic DNA via primer walking. Since reading lengths of $>600 \mathrm{bp}$ were very difficult to obtain in the early days of genomic sequencing it is not too surprising in 


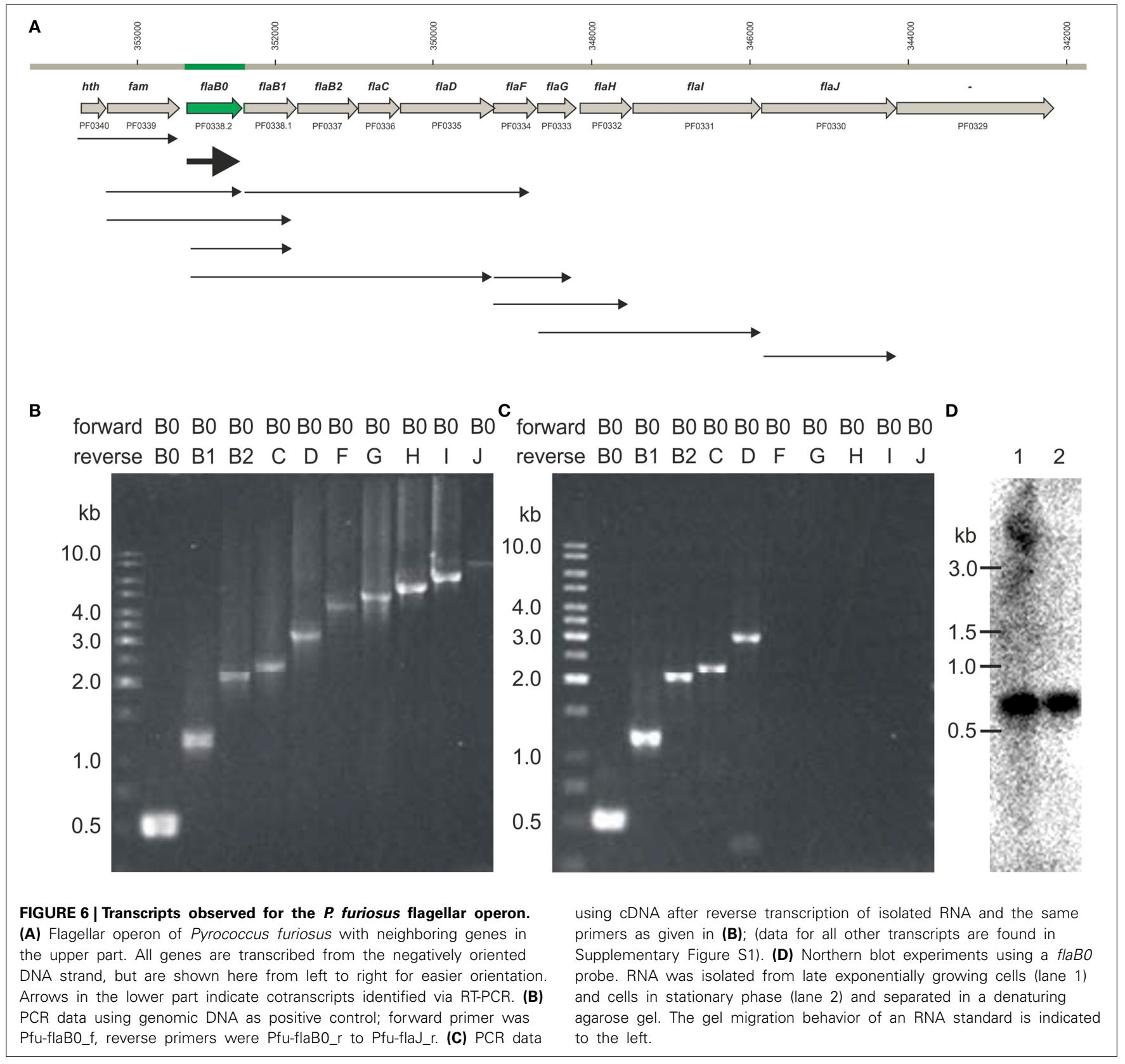

retrospect that flaBO was not detected in the original published P. furiosus genome sequence (Robb et al., 2001).

\section{FlaBO IS THE MAJOR FLAGELLIN OF $P$. FURIOSUS FLAGELLA}

The here newly described gene flaBO codes for the major flagellin of $P$. furiosus, whereas FlaB1 and FlaB2 are only minor flagellins. This statement is supported by the fact that one major glycoprotein of ca. $30 \mathrm{kDa}$ was identified in all flagellar preparations isolated over a period of nearly 10 years; the N-terminal sequence of this protein read as AVGIGTLIVF which can be matched clearly to FlaB0. There was no heterogeneity at position 2 and the presence of FlaB1 and FlaB2 was proven only by use of specific antibodies. In further experiments we were able to show that antisera raised against the least conserved part of the flagellins FlaB1 and FlaB2 labeled CsCl-gradient purified flagella mostly on their ends, whilst an antiserum raised against purified flagella reacted much stronger over the whole length of flagella.

\section{REPOLYMERIZATION OF DENATURED FLAGELLA}

Flagellins derived from SDS- plus heat-denatured flagella could clearly be repolymerized into smaller aggregates and fibrillar structures via simple heat treatment. The ultrastructure and diameter of such fibrils differs obviously from that of purified flagella. This, however, is not too surprising if one takes into account that for flagella assembly most likely a platform containing (at least) the proteins FlaC, FlaD, FlaF, and FlaG is necessary in vivo (see Jarrell et al., 2013 and references therein). In addition this process is supposed to require ATP; in our hands repeated 


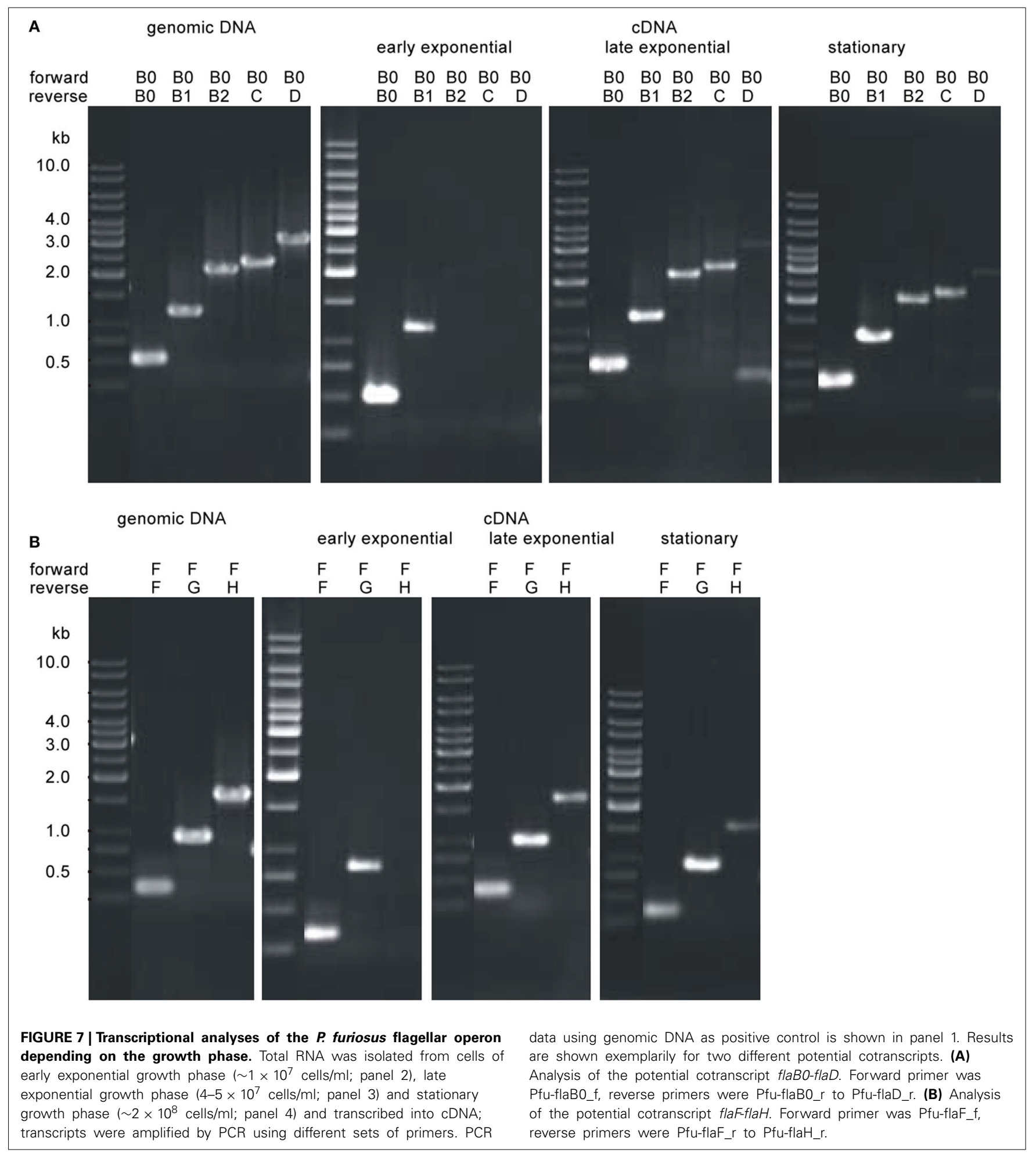

ATP addition to the in vitro repolymerization assays, however had no effect.

\section{THE FLAGELLAR OPERON OF VARIOUS P. FURIOSUS STRAINS}

Transcription of genes $p f 0329$ to $p f 0340$ is from the negatively oriented DNA strand, whilst the neighboring genes are transcribed form the positively oriented strand. Operon prediction using the Prokaryotic Operon DataBase (ProOpDB; Taboada et al., 2012) reveals two operons in this region encoding PF0340PF0339 and PF0338-PF0329, respectively. Therefore, we analyzed this part of the genome for transcription including the flagellar operon neighboring genes pf0329 and pf0340. Both, our RT-PCR 
experiments and Northern Blot analyses show that there is not a single cotranscript detectable for the genes inside the flagellar operon of $P$. furiosus, starting at flaBO (or even pf0340) and ending with flaJ (or pf0329). Rather, various cotranscripts were detected. Single transcripts were observed for flaBO and flaJ. From these results we conclude that the flagellar operon is composed of genes $p f 0340-p f 0330$, whereas the gene encoding the hypothetical protein PF0329 is not a part of the operon.

Possible explanations for the existence of various cotranscripts we identified are as follows. fam-flaB0, fam-flaB1: the specificity of the postulated methyltransferase is unknown; it potentially could modify FlaB0 and FlaB1 (and also FlaB2). Analyzing the publically available genomes of the genus Pyrococcus for the presence of an ortholog of the P. furiosus methyltransferase, we found the respective gene in all species directly upstream of the flagellin genes, supporting our hypothesis that the enzyme acts on flagellins. flaB0-flaD, flaB1-flaF: FlaC, FlaD (and FlaE, which is not present in $P$. furiosus) are argued to be necessary for flagella assembly (see e.g., Schlesner et al., 2009); therefore, a coexpression with the flagellins would be expected. flaF-flaG; flaF-flaH; flaG-flaI: FlaF and FlaG have been argued to be essential for expression of flagella (Jarrell et al., 2013). Since no direct data for the function of those proteins are available, any argument about cotranscription or direct interaction of encoded proteins would be pure speculation. FlaH, FlaI, and FlaJ are probably part of the secretion and motor complex of archaeal flagella (Jarrell et al., 2013). Structural and genetic studies of the ATPase FlaI of $S$. acidocaldarius revealed that the protein forms a hexameric crown-like ring; its conformational changes and interactions with membrane lipids and binding partners (mostly FlaJ) regulate assembly and rotation of flagella (Reindl et al., 2013). Hence we expected cotranscription of the corresponding genes. However, our results showed that flaJ is transcribed only as a single gene regardless of the growth phase. In contrast, the cotranscripts described herein differed depending on the growth phase; these findings are in line with our electron microscopic studies of $P$. furiosus cells showing that flagella are assembled particularly in late logarithmic phase (early exponential cells possess no or only few flagella; data not shown).

The absence of one single flagellar transcript is supported by data for other Archaea: a very good overview was given by Thomas et al. (2001) (see especially Figure 4, therein). In all cases, one or more major transcripts encoding the flagellins — FlaA and/or FlaB proteins - have been identified by Northern blots. Minor transcripts, argued to code for additional proteins FlaC to FlaJ have been found in all of these cases; transcripts not starting with flaA or flaB, however have not been analyzed. Also for Sulfolobus solfataricus a major transcript, encoding the flagellin FlaB has been found (Szabo et al., 2007), but again transcripts encoding further genes in the flagellar operon have not been characterized.

Because the three $P$. furiosus strains presented in this study show differences in the number of flagella and adhesion properties the question arose if their flagellar operons might be different and, most notably, if the flaBO gene is conserved. The genome of $P$. furiosus is known to be highly dynamic as proven for the genetically tractable strain COM1 (Bridger et al., 2012) and different
Pyrococcus strains originated from environmental samples (e.g., Escobar-Paramo et al., 2005; White et al., 2008). COM1 is derived from strain DSM $3638^{\mathrm{T}}$ by targeted gene disruption of the $p y r F$ locus (Lipscomb et al., 2011), it possesses 45 full or partial insertion sequences compared to 35 in strain DSM $3638^{\mathrm{T}}$, resulting in inactivation of 13 genes. In addition alterations in 102 of 2134 predicted genes were observed, together with major chromosomal rearrangements, deletions etc. (Bridger et al., 2012). Despite these proven changes in the genome, we found that flaBO is wellconserved in all three $P$. furiosus strains described in this study supporting our data that flaBO encodes the major $P$. furiosus flagellin. Differences in flagellation and adherence, therefore, might be caused by alterations in other regions of the genome and/or regulatory effects. In this context, we note to have shown earlier that flagella contribute to adhesion (Näther et al., 2006), but we also are aware of the fact that other archaeal cell surface appendages like pili (Jarrell et al., 2011), fibers (Müller et al., 2009), fimbriae (Thoma et al., 2008), and hami (Moissl et al., 2005) at least can contribute to adhesion to various surfaces.

\section{AUTHOR CONTRIBUTIONS}

Daniela J. Näther-Schindler, Simone Schopf, Annett Bellack, Reinhard Rachel, and Reinhard Wirth designed the study and analyzed the data. Research was performed by Daniela J. NätherSchindler, Simone Schopf, and Annett Bellack. Annett Bellack and Reinhard Wirth wrote the paper; all authors agreed to the final version.

\section{ACKNOWLEDGMENTS}

The expert technical help by E. Papst, Y. Bilek, T. Hader, and K. Eichinger is gratefully acknowledged. We thank Nadin Wimmer for cloning of FlaB2. This study was supported in its very early stages by a grant from the Deutsche Forschungsgemeinschaft (DFG WI731/10-1) to Reinhard Rachel and Reinhard Wirth.

\section{SUPPLEMENTARY MATERIAL}

The Supplementary Material for this article can be found online at: http://www.frontiersin.org/journal/10.3389/fmicb. 2014.00695/abstract

\section{REFERENCES}

Bayley, D. P., and Jarrell, K. F. (1999). Overexpression of Methanococcus voltae flagellin subunits in Escherichia coli and Pseundomonas aeruginosa: a source of archaeal preflagellin. J. Bacteriol. 181, 4146-4153.

Bellack, A. (2011). Cell Architecture and Flagella of Hyperthermophilic Archaea. Ph.D. thesis, University of Regensburg.

Bellack, A., Huber, H., Rachel, R., Wanner, G., and Wirth, R. (2011). Methanocaldococcus villosus sp. nov., a heavily flagellated archaeon adhering to surfaces and forming cell-cell contacts. Int. J. Syst. Evol. Microbiol. 61, 1239-1245. doi: 10.1099/ijs.0.023663-0

Bridger, S. L., Lancester, W. A., Poole, F. L., Schut, G. J., and Adams, M. W. W. (2012). Genome sequencing of a genetically tractable Pyrococcus furiosus strain reveals a highly dynamic genome. J. Bacteriol. 194, 4097-4106. doi: 10.1128/JB.00439-12

Chaban, B., Ng, S. Y. M., Kanbe, M., Saltzman, I., Nimmo, G., Aizawa, S.-I., et al. (2007). Systematic deletion analyses of the fla genes in the flagella operon identify several genes essential for proper assembly and function of flagella in the archaeon, Methanococcus maripaludis. Mol. Microbiol. 66, 596-609. doi: 10.1111/j.1365-2958.2007.05913.x

Escobar-Paramo, P., Ghosh, S., and DiRuggiero, J. (2005). Evidence for genetic drift in the diversification of a geographically isolated population of the 
hyperthermophilic archaeon Pyrococcus. Mol. Biol. Evol. 22, 2297-2304. doi: 10.1093/molbev/msi227

Fleischmann, R. D., Adams, M. D., White, O., Clayton, R. A., Kirkness, E. F., Kerlavage, A. R., et al. (1995). Whole-genome random sequencing and assembly of Haemophilus influenzae Rd. Science 269, 496-512. doi: 10.1126/science.7542800

Ghosh, A., and Albers, S.-V. (2011). Assembly and function of the archaeal flagellum. Biochem. Soc. Trans. 39, 64-69. doi: 10.1042/BST0390064

Herzog, B., and Wirth, R. (2012). Swimming behavior of selected species of Archaea. Appl. Environ. Microbiol. 78, 1670-1674. doi: 10.1128/AEM.06723-11

Jarrell, K. F., and Albers, S.-V. (2012). The archaellum: an old motiltiy structure with a new name. Trends Microbiol. 20, 307-312. doi: 10.1016/j.tim.2012.04.007

Jarrell, K. F., Ding, Y., Nair, D. B., and Siu, S. (2013). Surface appendages of Archaea: structure, function, genetics and assembly. Life 3, 86-117, doi: 10.3390/life3010086

Jarrell, K. F., Stark, M., Nair, D. B., and Chong, J. P. J. (2011). Flagella and pili are both necessary for efficient attachment of Methanococcus maripaludis to surfaces. FEMS Microbiol. Lett. 319, 44-50. doi: 10.1111/j.1574-6968.2011.02264.x

Kalmokoff, M. L., Jarrell, K. F., and Koval, S. F. (1988). Isolation of flagella from the Archaebacterium Methanococcus voltae by phase separation with Triton X-114. J. Bacteriol. 170, 1752-1758.

Lassak, K., Neiner, T., Ghosh, A., Klingl, A., Wirth, R., and Albers, S.-V. (2012) Molecular analysis of the crenarchaeal flagellum. Mol. Microbiol. 83, 110-124. doi: 10.1111/j.1365-2958.2011.07916.x

Lipscomb, G. L., Stirret, K., Schut, G. J., Yang, F., Jenney, F. E. Jr., Scott, R. A., et al. (2011). Natural competence in the hyperthermophilic archaeon Pyrococcus furiosus facilitates genetic manipulation: construction of markerless deletions of genes encoding the two cytoplasmic hydrogenases. Appl. Environ. Microbiol. 77, 2232-2238. doi: 10.1128/AEM.02624-10

Moissl, C., Rachel, R., Briegel, A., Engelhardt, H., and Huber, R. (2005). The unique structure of archaeal hami, highly complex cell appendages with nano-grappling hooks. Mol. Microbiol. 56, 361-370. doi: 10.1111/j.1365-2958.2005.04294.x

Müller, D. W., Meyer, C., Gürster, S., Küper, U., Huber, H., Rachel, R., et al. (2009). The Iho670 fibers of Ignicoccus hospitalis: a new type of archaeal cell surface appendage. J. Bacteriol. 191, 6465-6468. doi: 10.1128/JB.00858-09

Näther, D. J., Rachel, R., Wanner, G., and Wirth, R. (2006). Flagella of Pyrococcus furiosus: multifunctional organelles, made for swimming, adhesion to various surfaces, and cell-cell contacts. J. Bacteriol. 188, 6915-6923. doi: 10.1128/JB.00527-06

Ng, S. Y. M., Zolghadr, B., Driessen, A. J. M., Albers, S.-V., and Jarrell, K. J. (2008). Cell surface structures of Archaea. J. Bacteriol. 190, 6039-6047. doi: 10.1128/JB.00546-08

Patenge, N., Berendes, A., Engelhardt, H., Schuster, S. C., and Oesterhelt, D. (2001). The fla gene cluster is involved in the biogenesis of flagella in Halobacterium salinarum. Mol. Microbiol. 41, 653-663. doi: 10.1046/j.1365-2958.2001.02542.x

Rachel, R., Meyer, C., Klingl, A., Gürster, S., Heimerl, T., Wasserburger, N., et al. (2010). "Analysis of the ultrastructure of Archaea by electron microscopy," in Methods in Cell Biology, Vol. 96, ed T. Müller-Reichert (Philadelphia, PA: Elsevier), 47-69.

Reindl, S., Ghosh, A., Williams, G. J., Lassak, K., Neiner, T., Henche, A.-L., et al. (2013). Insights into FlaI functions in archaeal motor assembly and motility from structures, conformations, and genetics. Mol. Cell 49, 1069-1082. doi: 10.1016/j.molcel.2013.01.014

Robb, F. T., Maeder, D. L., Brown, J. R., DiRuggiero, J., Stump, M. D., Yeh, R. K., et al. (2001). Genomic sequence of the hyperthermophile Pyrococcus furiosus: implications for physiology and enzymology. Methods Enzymol. 330, 134-157. doi: 10.1016/S0076-6879(01)30372-5

Schlesner, M., Miller, A., Streif, S., Staudinger, W., Müller, J., Scheffer, B., et al. (2009). Identification of Archaea-specific chemotaxis proteins which interact with the flagellar apparatus. BMC Microbiol. 9:56. doi: 10.1186/1471-2180-9-56

Szabo, Z., Sani, M., Groeneveld, M., Zolghadr, B., Schelert, J., Albers, S.V., et al. (2007). Flagellar motility and structure in the hyperthermophilic archaeon Sulfolobus solfataricus. J. Bacteriol. 189, 4305-4309. doi: 10.1128/JB. 00042-07

Taboada, B., Ciria, R., Martinez-Guerrer, C. E., and Merino, E. (2012). ProOpDB: prokaryotic operon database. Nucleic Acids Res. 40, D627-D631. doi: 10.1093/nar/gkr1020

Thoma, C., Frank, M., Rachel, R., Schmid, S., Näther, D., Wanner, G., et al. (2008). The Mth60-fimbriae of Methanothermobacter thermoautotrophicus are functional adhesins. Environ. Microbiol. 10, 2785-2795. doi: 10.1111/j.14622920.2008.01698.x

Thomas, N. A., Bardy, S. L., and Jarrell, K. F. (2001). The archaeal flagellum: a different kind of prokaryotic motility structure. FEMS Microbiol. Rev. 25, 147-174. doi: 10.1111/j.1574-6976.2001.tb00575.x

Waege, I., Schmid, G., Thumann, S., Thomm, M., and Hausner, W. (2010). Shuttle vector-based transformation system for Pyrococcus furiosus. Appl. Environ. Microbiol. 76, 3308-3313. doi: 10.1128/AEM.01951-09

White, J. R., Escobar-Paramo, P., Mongodin, E. F., Nelson, K. E., and DiRuggiero, J. (2008). Extensive genome rearrangements and multiple horizontal gene transfer in a population of Pyrococcus isolates from Vulcano Island, Italy. Appl. Environ. Microbiol. 74, 6447-6451. doi: 10.1128/AEM.01024-08

Wirth, R. (2012). Response to Jarrell and Albers: seven letters less does not say more. Trends Microbiol. 20, 511-512. doi: 10.1016/j.tim.2012.07.007

Conflict of Interest Statement: The authors declare that the research was conducted in the absence of any commercial or financial relationships that could be construed as a potential conflict of interest.

Received: 30 September 2014; accepted: 24 November 2014; published online: 11 December 2014

Citation: Näther-Schindler DJ, Schopf S, Bellack A, Rachel R and Wirth R (2014) Pyrococcus furiosus flagella: biochemical and transcriptional analyses identify the newly detected flaB0 gene to encode the major flagellin. Front. Microbiol. 5:695. doi: $10.3389 /$ fmicb.2014.00695

This article was submitted to Microbial Physiology and Metabolism, a section of the journal Frontiers in Microbiology.

Copyright (C) 2014 Näther-Schindler, Schopf, Bellack, Rachel and Wirth. This is an open-access article distributed under the terms of the Creative Commons Attribution License (CC BY). The use, distribution or reproduction in other forums is permitted, provided the original author(s) or licensor are credited and that the original publication in this journal is cited, in accordance with accepted academic practice. No use, distribution or reproduction is permitted which does not comply with these terms. 